\title{
La mort
}

programmée de

la sage-femme?

Anne-Marie Moulin

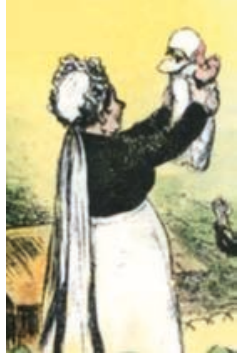

CNRS UMR SPHERE 7219

Université Paris 7, bâtiment

Condorcet, 4 rue Elsa Morante, 75013 Paris, France.

anne.saintromain@gmail.com
La sage-femme, un métier en voie de disparition ? Lappelexperte des accouchements. Telle est en tout cas la définition de l'Académie française en 1694 : «celle dont le métier est d'accoucher les femmes. » Leurs revendications actuelles suggèrent-elles la clôture d'un cycle qui les institua professionnelles de l'accouchement, détrônant les matrones qui, depuis le fond des âges, prêtaient secours aux parturientes?

C'est cette histoire, du décret de ventôse 1803 aux lois de 1917, que Nathalie Sage-Prouchère reconstitue pour la France à partir d'archives départementales et nationales minutieusement inventoriées [1]. Elle suit les méandres d'une administration tiraillée entre des objectifs contradictoires, par exemple encourager les initiatives locales pour la formation et maintenir le centralisme parisien, face à un vrai problème : la mortalité maternelle et infantile persistante.

Tout au long $d u x^{e} x^{e}$ siècle, la même préoccupation des pouvoirs publics transparaît : maintenir la subordination de la sage-femme au chirurgien et des femmes aux hommes... Suspectes, en raison de leur familiarité avec les choses du sexe et de la vie, en même temps que détentrices d'un savoir en pleine évolution qui élargit leurs compétences au-delà de l'accouchement, à la gynécologie et à la pédiatrie, les sages-femmes ont connu, au cours $\mathrm{du} x \mathrm{x}^{\mathrm{e}}$ siècle, une lente ascension sociale, comparable à celle des institutrices. La loi de 1892, abolissant les officiers de santé, les consacrait enfin comme un corps professionnel apportant le progrès médical au fin fond des campagnes où elles étaient seules à exercer désormais.

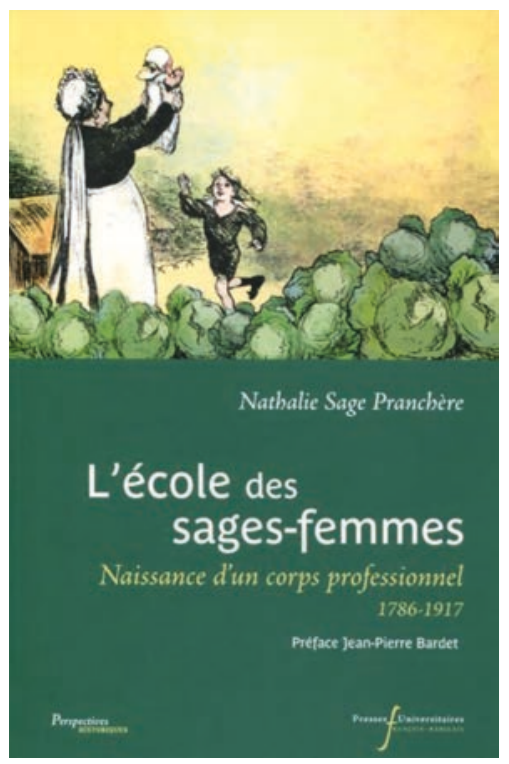

\section{RÉFÉRENCE}

1. Sage Pranchère N. L'école des sages-femmes. Naissance d'un corps professionnel 1786-1917. Tours : Presses Universitaires François-Rabelais de Tours, 2017.

TIRÉS À PART

A.M. Moulin 